\title{
ACORDOS DE MEDIAÇÃO E PERSPECTIVAS DE APLICAÇÃO DA RECENTE CONVENÇÃO DE SINGAPURA NO BRASIL
}

\author{
MEDIATION AGREEMENTS AND PROSPECTS FOR THE APPLICATION OF THE \\ RECENT SINGAPORE CONVENTION IN BRAZIL
}

Marília Pedroso Xavier1

Juliana Leticia Suttili Carniel ${ }^{2}$

Ana Carolina Martinez Bazia 3

\begin{abstract}
RESUMO: A assinatura da Convenção das Nações Unidas sobre Termos de Acordos Internacionais Resultantes de Mediação (Convenção de Singapura) pelo Brasil demonstra mais um avanço para o reconhecimento dos MASCs no país. Por isso, o propósito deste artigo é analisar os próximos passos a serem adotados para a efetiva integração da Convenção ao ordenamento jurídico nacional. Para tanto, adotou-se o método dedutivo, com revisão bibliográfica de textos nacionais e internacionais, que dão as primeiras impressões sobre a Convenção. No primeiro capítulo, foi verificada a compatibilidade da Lei de Mediação brasileira com a Convenção de Singapura, bem como o que ainda precisa ser feito para o ingresso desta no ordenamento. No segundo capítulo, foram trazidos alguns desafios dos tribunais do país acerca da eventual execução dos acordos submetidos à Convenção. No terceiro capítulo, foram sugeridas algumas cautelas para minimizar os riscos envolvidos nos acordos fruto de mediação internacional. Apesar das dúvidas que ainda persistem acerca da ratificação e efetiva aplicação da Convenção no Brasil, as perspectivas são otimistas, dada a convergência já existente e o contexto globalizado vivido, sendo esperadas a disseminação e consolidação da mediação no contexto do comércio internacional.
\end{abstract}

Palavras-chave: Mediação. Mediação internacional. Convenção de Singapura. Brasil. Contratos comerciais. MASC.

1 Professora da graduação e da pós-graduação stricto sensu da Faculdade de Direito da Universidade Federal do Paraná (UFPR). Doutora em Direito Civil pela Universidade de São Paulo (USP). Mestre e graduada em Direito pela UFPR. Coordenadora de Direito Privado da Escola Superior de Advocacia do Paraná. Membro da Diretoria Paranaense do Instituto Brasileiro de Direito de Família. Diretora do Instituto Brasileiro de Direito Contratual (IBDCONT). Advogada. Mediadora. Autora da obra "Contrato de Namoro: amor líquido e direito de família mínimo" publicada pela Editora Fórum. Currículo Lattes: http://lattes.cnpq.br/9828738337740597. ORCID: https://orcid.org/0000-0002-1307-3116. E-mail: marilia@pxadvogados.com.br.

2 Pós-graduanda em Direito de Família e Sucessões pelo Instituto Imadec. Graduada em Direito pela Universidade Federal do Paraná (UFPR). Membro do Grupo de Mediação e Negociação da UFPR. Advogada. Currículo Lattes: http://lattes.cnpq.br/0073345726162394. ORCID: https://orcid.org/0000-0002-1307-3116. Email: julianalscarniel@gmail.com.

3 Graduada em Direito pela Universidade Federal do Paraná (UFPR). Membro do Grupo de Mediação e Negociação da UFPR. Advogada. Currículo Lattes: http://lattes.cnpq.br/2345231871952936. ORCID: https://orcid.org/0000-0002-1307-3116. E-mail: ana_mbazia@hotmail.com. 
ABSTRACT: The signing of the United Nations Convention on International Settlement Agreements Resulting from Mediation (Singapore Convention) by Brazil represents one more step towards the recognition of ADRs in the country. Wherefore, the purpose of this article is to analyze the next steps to be taken for the effective integration of the Convention into the national legal system. Therefore, the deductive method was adopted, with a bibliographical review of national and international texts, which bring the first impressions of the Convention. In the first chapter, the compatibility of the Brazilian Mediation Law with the Singapore Convention was examined, as well as what still needs to be done for its entry into the legal system. In the second chapter, some challenges faced by the country's courts were raised regarding the eventual enforcement of the agreements submitted to the Convention. In the third chapter, some precautions were suggested to minimize the risks involved in the agreements resulting from international mediation. Despite the doubts that still persist about the ratification and effective application of the Convention in Brazil, perspectives are optimistic, given the existing convergence and the globalized context experienced. The dissemination and consolidation of mediation in the context of international trade are expected.

Keywords: Mediation. International mediation. Singapore Convention. Brazil. Commercial contracts. ADR.

Sumário: 1. Introdução; 2. Inserção da Convenção de Singapura no ordenamento jurídico brasileiro; 3. Desafios de aplicação da Convenção de Singapura pelos tribunais brasileiros; 4. O impacto da Convenção de Singapura para os mediandos; 5. Considerações finais; 6. Referências.

\section{INTRODUÇÃO}

A Convenção das Nações Unidas sobre Termos de Acordos Internacionais Resultantes de Mediação, mais conhecida por Convenção de Singapura sobre Mediação, é um importante marco para a disseminação da mediação a nível mundial. Considerando o contexto global de desenvolvimento de métodos autocompositivos, havia na comunidade de comércio internacional um anseio por maior segurança na exequibilidade dos acordos obtidos através de um processo de mediação, de modo semelhante à segurança proporcionada às sentenças arbitrais pela Convenção de Nova York de $1958 .^{4}$

Nesse sentido, a Convenção de Singapura veio para fornecer uma moldura normativa para o reconhecimento e execução dos acordos relativos a disputas de comércio internacional, possibilitando que Estados com diferentes sistemas jurídicos, sociais e econômicos possam dar exequibilidade aos acordos. A partir disso, cumpre-se o objetivo de incentivar a utilização

4 Trata-se da Convenção sobre o Reconhecimento e a Execução de Sentenças Arbitrais Estrangeiras, a qual foi recepcionada pelo ordenamento brasileiro através do Decreto $n^{\circ} 4.311 / 2002$. 
da mediação em disputas comerciais transfronteiriças e o desenvolvimento de relações econômicas internacionais harmoniosas.

A Convenção é resultado dos trabalhos desenvolvidos pelo Working Group II da UNCITRAL (Comissão de Direito Comercial Internacional das Nações Unidas) entre os anos de 2015 e 2018. Após diversos debates, houve a consolidação de um texto final, o qual foi recomendado para a Assembleia Geral da ONU em 25 de junho de 2018 e aceito por ela em 20 de dezembro de 2018. A assinatura da Convenção ocorreu em 7 de agosto de 2019, em uma cerimônia realizada em Singapura, ocasião na qual foi assinada por 46 países. Até o final de junho de 2021, a Convenção contava com 5 ratificações, 1 aprovação e 54 assinaturas 5 , tendo entrado em vigor em 12 de setembro de 2020, 6 meses após as três primeiras ratificações (Fiji, Singapura e Qatar).

O Brasil assinou a Convenção de Singapura no dia 4 de junho de 2021 (BRASIL, 2021), representando um primeiro passo de grande importância para que a cultura da autocomposição seja reforçada no país, instigando o uso da mediação em conflitos comerciais internacionais.

Pensando nos próximos passos a serem dados, o presente artigo buscará analisar, num primeiro momento, qual o caminho a ser seguido do ponto de vista legislativo, inclusive refletindo sobre a compatibilidade da atual Lei de Mediação com os ditames da Convenção em determinados aspectos. Em seguida, será analisada a perspectiva da aplicação da Convenção pelos tribunais brasileiros, ponderando sobre os desafios da execução dos acordos internacionais obtidos através de mediação. Posteriormente, serão trazidas algumas considerações para os futuros mediandos que optarão por se utilizar da Convenção.

O objetivo do presente artigo é dar um panorama sobre como se dará a inserção e a aplicação da Convenção de Singapura em solo brasileiro, bem como identificar alguns

5 Equador, Fiji, Qatar, Arábia Saudita e Singapura já ratificaram a Convenção; Bielorrússia deu aprovação; Assinaram a Convenção, além dos países anteriores: Afeganistão, Armênia, Benin, Brasil, Brunei, Chade, Chile, China, Congo, República Democrática do Congo, Colômbia, Eswatini, Gabão, Georgia, Gana, Granada, GuinéBissau, Haiti, Honduras, Índia, Irã, Israel, Jamaica, Jordânia, Cazaquistão, Laos, Malásia, Maldivas, Maurício, Montenegro, Nigéria, Macedônia do Norte, Palau, Paraguay, Filipinas, Coréia, Ruanda, Samoa, Sérvia, Serra Leoa, Sri Lanka, Timor Leste, Turquia, Uganda, Ucrânia, EUA, Uruguai e Venezuela. A consulta atualizada dos países signatários está disponível em: <https://uncitral.un.org/en/texts/mediation/conventions/international_settlement_agreements/status>. Acesso em: 17 jun. 2021. 
desafios e oportunidades. A metodologia utilizada é a dedutiva, sendo realizada a análise de diversos textos doutrinários nacionais e internacionais relacionados à temática.

Apesar de ser um instrumento recente, há grandes expectativas para a rápida disseminação e utilização da Convenção de Singapura. Por isso, é preciso estar atento aos desafios que surgirão, sempre tendo em mente a promoção de uma cultura de pacificação social, de fortalecimento das relações e de popularização dos métodos autocompositivos.

\section{INSERÇÃO DA CONVENÇÃO DE SINGAPURA NO ORDENAMENTO JURÍDICO BRASILEIRO}

A assinatura da Convenção de Singapura pelo Brasil está inserida num movimento de desenvolvimento dos métodos adequados de solução de conflitos (MASCs) no país que ocorre há mais de uma década. A Resolução no 125/2010 do Conselho Nacional de Justiça (CNJ) foi um grande marco para a catalisação da utilização dos MASCs, passando a fazer parte do cotidiano da comunidade jurídica. Tal resolução dispõe sobre a Política Judiciária Nacional de tratamento adequado dos conflitos de interesses no âmbito do Poder Judiciário, tendo previsto a criação de órgãos voltados aos métodos autocompositivos dentro dos tribunais e também estabelecido parâmetros para a formação de conciliadores e mediadores.

O ano de 2015 também foi decisivo para a promoção dos MASCs, pois nele foram promulgados o novo Código de Processo Civil (Lei $n^{\circ}$ 13.105/2015) e também a Lei de Mediação (Lei $\mathrm{n}^{\circ}$ 13.140/2015). No primeiro diploma se destacam o incentivo à solução consensual de conflitos (art. $3^{\circ}, \S \S 2^{\circ}$ e $3^{\circ}$ ), a previsão de uma audiência de mediação ou conciliação (art. 334), bem como a diferenciação entre mediadores e conciliadores (art. 165). Já o segundo se sobressai por regular a mediação como meio de solução de controvérsias entre particulares, bem como a autocomposição de conflitos no âmbito da administração pública. Desde então diversas outras leis 6 também passaram a incluir ou mencionar os meios autocompositivos em seus dispositivos.

6 Dois exemplos são as Leis $\mathrm{n}^{\circ} 14.112 / 2020$ e $\mathrm{n}^{\circ} 14.133 / 2021$. A primeira alterou a Lei de Falências e Recuperação de Empresas (Lei $\left.n^{\circ} 11.101 / 2005\right)$ ao incluir uma seção específica sobre conciliações e mediações antecedentes ou incidentais aos processos de recuperação judicial. Já a segunda é a nova Lei de Licitações e Contratos Administrativos, inovando ao trazer um capítulo específico sobre os meios alternativos de resolução de controvérsias, prevendo a possibilidade de utilização da conciliação, mediação, comitê de resolução de disputas (dispute boards) e arbitragem. 
Nesse sentido, caso a Convenção de Singapura seja ratificada pelo Brasil, ela passará a fazer parte deste corpo legislativo relativo a meios adequados de resolução de conflitos. Pensando nisso foram elencados alguns tópicos-chave nos quais pode ser identificada grande compatibilidade entre a Convenção e a Lei de Mediação, esta última sendo a lei mais específica sobre este método autocompositivo no Brasil.

Iniciando pela definição de mediação, para a Convenção de Singapura (art. $2^{\circ}$, item 3) esta é um processo através do qual "as partes tentam chegar a um acordo amigável para sua disputa, com a assistência de uma terceira pessoa ou pessoas (“o mediador") sem autoridade para impor às partes uma solução para o conflito". 7 Já a Lei de Mediação considera mediação "a atividade técnica exercida por terceiro imparcial sem poder decisório, que, escolhido ou aceito pelas partes, as auxilia e estimula a identificar ou desenvolver soluções consensuais para a controvérsia", conforme seu art. $1^{\circ}$, parágrafo único. Da análise das duas definições, percebe-se como ponto comum o destaque dado à presença de um terceiro sem poder decisório, o qual auxilia e presta assistência às partes na busca por uma solução amistosa.

Schnabel (2019a, p. 15-19) aponta que a Convenção buscou ter uma definição ampla de mediação, num estilo guarda-chuva que abarcasse diversos tipos de processos, justamente para coadunar com o objetivo de ampliar sua utilização. Nesse sentido, o autor destaca que no processo de redação da Convenção foram considerados irrelevantes o nome dado ao processo $^{8}$, a origem do processo de mediação 9 e também aspectos relativos à quantidade de participação do mediador no processo. ${ }^{10}$ Ainda, a definição de mediação prevista na lei brasileira tem as especificidades de indicar que o terceiro precisa ser imparcial e que deve ser escolhido ou aceito pelas partes, sendo que a definição guarda-chuva da Convenção também é capaz de abarcá-las.

7 No presente trabalho as referências ao texto da Convenção são feitas com base na tradução livre de Carla Araújo Demchuk, Paul Eric Mason e Nazareth Serpa. (Disponível em: >https://imimediation.org/2019/11/29/singapore-convention-text-in-portuguese/>. Acesso em: 18 jun. 2021). O texto oficial em inglês está disponível em: <https://uncitral.un.org/sites/uncitral.un.org/files/singapore_convention_eng.pdf>. Acesso em: 17 jun. 2021.

8 Não se consideraram distinções entre mediação, conciliação ou outros processos, eis que o uso de um mesmo termo poderia ser feito de diferentes formas em culturas jurídicas diversas.

9 O processo de mediação pode se originar por força de uma cláusula de mediação, por concordância das partes após o surgimento do conflito, ou ainda se foi indicado por alguma autoridade judicial.

10 Quanto ao aspecto da quantidade de participação do mediador, tem-se a hipótese de as partes resolverem boa parte da contenda por elas próprias, contando com uma participação pontual do mediador. Nesse caso, ainda que com uma participação pequena do mediador, houve um processo de mediação. 
Um segundo aspecto versa sobre o objeto da mediação. Para estar abrigado pelo escopo da Convenção, o acordo obtido precisa se tratar de uma disputa comercial qualificada como internacional (art. $1^{\circ}$, item 1), não versando sobre questões relacionadas à seara consumerista, familiarista, de sucessões ou trabalhista (art. $1^{\circ}$, item 2). Chong e Alexander (2019b, p. 30) apontam que estas exclusões, além de dar ênfase ao foco da UNCITRAL em questões comerciais, estão relacionadas a situações em que há desequilíbrio de poder entre as partes, sendo que as mais vulneráveis demandariam proteção, o que pode ser feito de formas diferentes por cada país e implicar em dificuldades de aplicação.

Por sua vez, a Lei de Mediação traz em seu artigo $3^{\circ}$, caput, que o objeto da mediação abarca "conflito que verse sobre direitos disponíveis ou sobre direitos indisponíveis que admitam transação" 11 , sendo que, acerca destes últimos direitos, em razão do art. $3^{\circ}, \S 2^{\circ}$, é exigida a homologação em juízo e oitiva do Ministério Público. Com tais previsões, pretendese evitar que direitos relacionados à proteção de interesse público sejam regidos por uma ordem negociada. Ademais, no caso de haver um desequilíbrio entre as partes, caberia ao mediador analisar se tal situação seria impeditiva para a realização da mediação (ALMEIDA; PANTOJA; ANDRADE, 2016, p. 82-83).

A partir desta análise verifica-se que o espectro do objeto da mediação é mais amplo na Lei de Mediação do que na Convenção de Singapura, ressaltando-se que os direitos comerciais transigidos na seara internacional estão abarcados dentro dos direitos disponíveis, os quais também são transigíveis.

Um terceiro aspecto diz respeito ao mediador em si. A Convenção de Singapura não aborda diretamente aspectos relativos ao mediador, apenas trazendo menções no art. $5^{\circ}$, itens 1 e) e f), sobre motivos para recusa do enforcement pela autoridade competente. Neles são mencionados, respectivamente, a ocorrência de "uma séria violação por parte do mediador dos padrões aplicáveis ao mediador ou à mediação" e a ocorrência de "falha do mediador na divulgação para as partes de circunstâncias que provocaram dúvidas justificáveis quanto à imparcialidade ou independência do mediador".

11 Acerca da discussão sobre os limites para os direitos disponíveis e dos indisponíveis transigíveis é importante a reflexão trazida por Fernanda Tartuce, destacando que "sob o manto da indisponibilidade, podem ser encontrados direitos de diferentes matizes", com maior ou menor rigor legal recaindo sobre eles. É certo que os parâmetros legais devem ser observados no que tange aos direitos indisponíveis, mas quando não há um regramento mais específico de determinadas situações, se verifica um espaço mais amplo para a negociação (TARTUCE, 2018, p. 31). 
Conforme discutido pelo Working Group II (CHONG; ALEXANDER, 2019b, p. 114), a ideia era que a Convenção tivesse uma abordagem inclusiva quanto ao aspecto de standards aplicáveis ao mediador e à mediação, deixando um espaço de abertura para as diferentes regulações de cada Estado-membro ${ }^{12}$. Nesse sentido há que ser mencionada uma aproximação com o art. $9^{\circ}$ da Lei de Mediação. Ainda que o mesmo se refira apenas a mediadores extrajudiciais, não é exigido destes que sejam inscritos ou façam parte de conselhos, entidades de classe ou associações. O foco principal do artigo está na confiança depositada pelas partes no mediador, dele sendo exigido, de forma genérica, que seja capacitado para fazer mediação.

Portanto, resta verificado que tanto a Convenção quanto a Lei de Mediação não listam requisitos específicos para a atuação conforme do mediador fora do ambiente judicial. Todavia, existem códigos de conduta tanto a nível doméstico ${ }^{13}$ quanto a nível internacional ${ }^{14}$ que podem ser utilizados como parâmetro para a interpretação dos referidos artigos.

Acerca do art. $5^{\circ}, 1$, f) da Convenção, o paralelo com a Lei de Mediação pode ser trazido através da análise do seu art. $5^{\circ}$. O caput determina que se aplicam ao mediador as mesmas condições de impedimento e suspeição aplicadas aos juízes ${ }^{15}$, ao passo que o parágrafo único prevê o dever de revelação de circunstâncias que possam afetar a imparcialidade do mediador.

A partir disso, tem-se que ambos os diplomas se preocuparam em assegurar a inexistência de dúvidas das partes acerca da imparcialidade do mediador, já que uma atuação parcial pode fazer com que uma das partes sofra prejuízos, dando ensejo para a anulação do acordo no âmbito doméstico (TILKIAN, 2016, p. 93) e recusa da execução pela autoridade competente no âmbito da Convenção de Singapura.

12 Schnabel, por sua vez, menciona que imparcialidade, independência, confidencialidade e tratamento justo das partes seriam exemplos de itens abarcados pelos padrões éticos do art. $5^{\circ}, 1$, e) da Convenção. Todavia, não poderia ser exigido o cumprimento de requisitos indicados a posteriori pela autoridade competente para executar o acordo (SCHNABEL, 2019a, p. 51).

13 É exemplo o Anexo III da Resolução no 125/2010 CNJ, que traz o Código de Ética de Conciliadores e Mediadores Judiciais.

14 São exemplos os códigos de conduta de instituições reconhecidas internacionalmente, como a International Mediation Institute, cujo código de conduta pode ser consultado em: <https://imimediation.org/practitioners/code-professional-conduct/>. Acesso em: 21 jun. 2021.

15 Os motivos de impedimento e suspeição são trazidos, respectivamente, nos artigos 144 e 145 do Código de Processo Civil. 
Uma outra semelhança identificada entre os dois diplomas é a previsão da possibilidade de uso de meios tecnológicos para a realização do acordo, abrindo caminho para a utilização dos ODRs. ${ }^{16} \mathrm{Na}$ Convenção as menções a comunicações eletrônicas aparecem tanto na definição do que é considerado um acordo escrito 17 quanto na explicação para os requisitos necessários para o acordo. 18 Como explica Schnabel (2019a, p. 29), tais trechos foram incluídos na Convenção justamente para evitar dúvidas se seria possível realizar acordos através de meios eletrônicos. Chong e Alexander (2019b, p. 82), por sua vez, explicitam que não foi mencionada uma categoria específica de tecnologia acerca da forma de assinatura eletrônica, justamente porque há uma gama muito ampla de formas e métodos tecnológicos para realizar tal ato, não havendo a intenção de limitar possibilidades.

A Lei de Mediação, a seu turno, também dá abertura para a utilização dos ODRs através do art. 46, caput, que prevê que a "mediação poderá ser feita pela internet ou por outro meio de comunicação que permita a transação à distância, desde que as partes estejam de acordo." Ademais, o parágrafo único do referido artigo faculta a submissão de partes domiciliadas no exterior às regras estabelecidas pela Lei de Mediação, podendo ser de grande valia para as mediações comerciais internacionais.

Há que se destacar que a abertura dada aos ODRs nos dois diplomas se demonstrou muito acertada, pois não impuseram definições estritas, dando margem para absorver mudanças relacionadas ao desenvolvimento de novas tecnologias. Ademais, o atual contexto pandêmico, com a limitação das comunicações presenciais, apenas acelerou a popularização e utilização de métodos de comunicação virtual. ${ }^{19}$

16 "Online Dispute Resolution (ODR) is the application of information and communication technology to the prevention, management and resolution of disputes." Em tradução livre, a Resolução de Disputas Online é a utilização de tecnologias da informação e comunicação para a prevenção, gestão e resolução de disputas (KATSH; RULE, 2016, p. 329).

17 Para ser considerado acordo escrito, basta que o conteúdo da comunicação eletrônica consiga estar disponível para ser usado posteriormente como referência do que foi acordado. Um exemplo muito comum é a utilização de e-mails (art. $2^{\circ}$, item 2 da Convenção de Singapura).

$18 \mathrm{O}$ art. $4^{\circ}$, item 2 da Convenção aborda alguns aspectos sobre a assinatura através de meios eletrônicos. Um método deve ser utilizado para identificar as partes ou o mediador e para indicar a intenção das partes ou do mediador em relação às informações contidas na comunicação eletrônica. O método precisa ser adequado às circunstâncias e confiável ou provar que foi capaz de demonstrar os requisitos de identidade das partes e suas intenções.

19 Uma das preocupações levantadas acerca da vagueza do art. 46 da Lei de Mediação está relacionada à regulação de critérios de qualidade, garantindo o funcionamento eficaz, independente, transparente, justo e sem entraves da mediação (PAUMGARTTEN, 2016, p. 270). 
Em resumo, resta claro o alinhamento entre a Lei de Mediação e a Convenção de Singapura quanto a aspectos de definição e objeto da mediação, mediador 20 e uso de meios tecnológicos.

Por fim, aborda-se a possibilidade de executar acordos envolvendo países, órgãos governamentais e seus representantes. A Convenção traz em seu art. $8^{\circ}$, item 1, a), a possibilidade dos Estados-membro fazerem uma declaração e optarem que a Convenção não se aplique a acordos nos quais sejam parte ou estejam envolvidos órgãos governamentais ou seus representantes. ${ }^{21}$ Além de o Brasil ter assinado Convenção sem estabelecer semelhantes reservas, é improvável que na eventual ratificação sejam elencadas reservas nesse sentido. Isto porque o país já conta com diversas leis esparsas favoráveis à utilização de meios autocompositivos pela administração pública, além da Lei de Mediação propriamente dita. 22

Portanto, diante de todo o exposto, entende-se que não existem dissonâncias significativas que obstem a completa recepção da Convenção de Singapura no ordenamento jurídico brasileiro. Assim, passa-se a analisar qual o percurso legislativo que ainda precisa ser percorrido para que isto se concretize, contando a Convenção com plena aplicabilidade após sua ratificação. 23

20 Cabe ressaltar que a Lei de Mediação traz várias outras previsões acerca do mediador, mas estas não foram analisadas aqui de forma aprofundada justamente para manter o paralelo com os dispositivos da Convenção. Fazse, portanto, uma breve menção ao art. $7^{\circ}$ da Lei de Mediação, o qual impede que o mediador atue posteriormente como árbitro em processo no qual atuou como mediador. Tal artigo apresenta incompatibilidade com o art. 13 da UNCITRAL Model Law on International Commercial Mediation and International Settlement Agreements Resulting from Medition, o qual prevê a possibilidade de atuação de uma mesma pessoa como mediadora e árbitra, desde que as partes tenham consentido para tal. Esta Model Law foi elaborada pelo Working Group II da UNCITRAL juntamente com a Convenção de Singapura, com o objetivo de servir de modelo de legislação a ser adotada internamente pelos países. Ela pode ser adotada com ou sem modificações pelos países, portanto, não possui caráter vinculante, sendo apenas um norte para a produção de legislação interna na temática. Assim, por mais que haja esta sugestão legislativa por parte da UNCITRAL, o Brasil já conta com uma Lei de Mediação, não devendo esta pequena incompatibilidade ser vista como óbice para aplicação da Convenção em si. Disponível em: 〈https://uncitral.un.org/sites/uncitral.un.org/files/media-documents/uncitral/en/annex_ii.pdf〉. Acesso em: 17 jun. 2021.

21 Até junho de 2021 apenas Irã (assinou), Belarus (aprovou) e Arábia Saudita (ratificou) apresentaram declarações no sentido de que a Convenção não se aplicará para mediações nas quais eles sejam partes ou que envolvam órgãos governamentais ou seus representantes.

22 A Lei de Mediação conta com um capítulo específico sobre a autocomposição de conflitos em que é parte pessoa jurídica de direito público. Um exemplo de lei esparsa é a já mencionada Lei de Licitações e Contratos Administrativos (Lei n ${ }^{\circ} 14.133 / 2021$ ).

23 Apenas com a assinatura, estágio em que a Convenção se encontra agora no Brasil, o documento internacional ainda não possui força vinculante. 
Nesse sentido, a primeira coisa a ser destacada é que o direito brasileiro adotou o modelo chamado multifásico, no qual a vigência do tratado em solo brasileiro depende de outros atos para além da assinatura (SOARES, 2019, p. 1-3). Para que o processo avance para internalização no ordenamento brasileiro, a etapa após a assinatura é a submissão à apreciação do Congresso Nacional, que é solicitada mediante uma mensagem do Presidente da República, acompanhada do inteiro teor da Convenção e da exposição de motivos. A tramitação é iniciada na Câmara dos Deputados, passando posteriormente pelo Senado. São realizadas discussões pelas Comissões de Constituição, Justiça e Cidadania e de Relações Exteriores, em ambas as casas, além de outras comissões temáticas se necessário (REZEK, 2018, p. 91).

Havendo aprovação parlamentar, o texto do tratado é então assinado pelo Presidente do Senado e publicado no Diário Oficial da União. A etapa seguinte engloba a sanção presidencial, a promulgação pelo Presidente da República e a publicação do texto do tratado, por meio de decreto do chefe do Executivo. Tais atos permitem que seja feita a ratificação, isto é, a entrega ao depositário da Convenção, que no caso é o Secretário-Geral das Nações Unidas (art. $10^{\circ}$ da Convenção de Singapura). A partir deste momento é que se contará o início da vigência - e, portanto, obrigatoriedade de observância - da Convenção no país, o que, segundo a própria Convenção de Singapura, se dará seis meses depois (art. 14, item 2) (MAZZUOLI, 2021, p. 80).

Observa-se, também, a absoluta discricionariedade do Estado, inclusive, em não se vincular à Convenção, mesmo após sua assinatura, inexistindo qualquer obrigatoriedade de ratificação, muito embora possa ser vista no cenário internacional como politicamente inoportuna ou inamistosa (REZEK, 2018, p. 78). Caso o Estado-membro desista de continuar vinculado à Convenção de Singapura após ter efetuado a ratificação, há a possibilidade de denunciá-la, nos moldes do art. 16.

Diante do exposto, nota-se um longo e burocrático caminho para o ingresso definitivo da Convenção de Singapura no ordenamento jurídico brasileiro. Contudo, Chong e Alexander (2019b, p. 18) mencionam o potencial de a Convenção de Singapura encorajar Estados a desenvolver suas capacidades institucionais e regulatórias, a estabelecer regras para os prestadores de serviços de mediação e a construir uma infraestrutura capaz de integrar os meios tecnológicos ao ambiente de mediação.

Nesse sentido, pode-se dizer que o Brasil já conta com um desenvolvimento significativo de instrumentos desde a edição da Resolução nº 125/2010 do CNJ. Este histórico 
de produção legislativa é de grande valia quando se considera a possibilidade dos Estadosmembro da Convenção se tornarem polos de mediação perante a comunidade de comércio internacional.

Todavia, para além do trâmite legislativo e do desenvolvimento das instituições relacionadas à mediação, também é preciso prestar atenção a como os acordos abarcados pelo escopo da Convenção serão executados no Brasil. Isto certamente englobará a atuação dos tribunais brasileiros, tema que será desenvolvido no próximo capítulo.

\section{DESAFIOS DE APLICAÇÃO DA CONVENÇÃO DE SINGAPURA PELOS TRIBUNAIS BRASILEIROS}

Neste capítulo os olhares se voltam para uma análise prática da Convenção de Singapura, buscando entender como será aplicada no cotidiano do Judiciário nacional e quais os desafios vindouros. Tal análise se desdobra, principalmente, em três aspectos: processuais, materiais e o acúmulo de processos no Poder Judiciário. Iniciando pelos aspectos processuais, a executoriedade do acordo firmado por meio da Convenção será um dos primeiros desafios, isso porque o CPC/15 prevê um rol taxativo (MARINONI; ARENHART; MITIDIERO, 2021, p. 656) de documentos que são considerados títulos executivos extrajudiciais, conforme o art. 784, CPC.

Dentre eles há o instrumento de transação referendado por mediador credenciado por tribunal (art. 784, IV, CPC). Nada obstante, a doutrina processual tende a interpretar restritivamente a apenas aqueles mediadores presentes no cadastro nacional (MARINONI; ARENHART; MITIDIERO, 2021, p. 657). ${ }^{24}$ Dessa forma, não estariam abarcados os acordos cuja assinatura decorre de mediador de câmara privada ou ad hoc.

Importante ressaltar que a Convenção determina que o acordo deve ser escrito. Isso permitiria às partes a efetivação do contrato mediante ação monitória (art. 700 e seguintes do CPC). Contudo, tal solução demonstraria pouco efeito prático, pois um acordo internacional obtido através da Convenção teria a mesma força executiva que um acordo obtido na ausência

24 Conforme coloca o próprio CNJ: "O Cadastro Nacional de Mediadores Judiciais e Conciliadores (CCMJ) foi desenvolvido pelo Conselho Nacional de Justiça (CNJ) para atender ao disposto no artigo 167 da Lei $\mathrm{n}$. 13.105/2015 (Código de Processo Civil) e no artigo 6º IX, da Resolução CNJ n. 125/2010, para garantir a qualidade e a padronização das informações prestadas aos jurisdicionados e para interligar os cadastros de todos os tribunais". Disponível em: <https://www.cnj.jus.br/programas-e-acoes/conciliacao-e-mediacao/perguntasfrequentes-7/cadastro-nacional-de-mediadores-judiciais-e-conciliadores-ccmj/>. Acesso em: 28 jun. 2021. 
desta ou de um simples contrato, mantendo a incerteza e os entraves existentes (VANISOVÁ, 2019, p. 10).

É certo que os $\S \S 2^{\circ}$ e $3^{\circ}$ do art. 784 do CPC vislumbram a possibilidade que os títulos sejam oriundos de país estrangeiro, dispensando qualquer homologação. A eficácia executiva, porém, apenas existe quando satisfeitos os requisitos de formação exigidos pela lei do lugar de sua celebração e quando o Brasil for indicado como o lugar de cumprimento da obrigação. Ou seja, exige-se uma avaliação das leis estrangeiras para que seja possível executar no Brasil. Perde-se, obviamente, tempo significativo apenas nesta análise e discussão.

Não bastasse isso, há que se notar que há, nesse ponto, um grande desafio. Isso porque a Convenção estipula expressamente a chamada "desnecessidade de sítio", isto é, a dispensabilidade de indicação do lugar da assinatura do acordo (CHONG; ALEXANDER, 2019a). Isto está bastante alinhado com a força motriz da própria Convenção - a mediação internacional - mas também com os ODRs. Estas novas formas de realização e assinatura do acordo, que podem ocorrer inclusive digitalmente, de diferentes partes do globo, dificultam a determinação do "lugar de celebração".

Nesse sentido, seria impossível determinar de qual país seriam os requisitos que tornam aquele acordo um título executivo, porque sequer se sabe qual lei estrangeira adotar como parâmetro. Os primeiros comentários acerca da Convenção indicam que tal escolha decorreu da lógica de que as partes podem desenhar soluções abstraídas, isto é, não vinculadas a um sistema legal específico. Mais do que isso, a intenção reside em emprestar executoriedade direta e internacional (CHONG; ALEXANDER, 2019b, p. 25-26).

Contudo, não sendo os acordos internacionais uma das hipóteses elencadas no art. 784, CPC, tampouco constando expressamente que a Convenção transfigura o acordo em título executivo - até em virtude dos diferentes tipos de enforcement emprestados pelos países signatários, há uma dificuldade de internalização prática do pretendido enforcement no Brasil. Sem uma alteração legislativa, poderia permanecer a interpretação de que, para tanto, seria necessário obedecer aos requisitos já existentes na lei processual brasileira, sem qualquer diferença efetiva.

Acredita-se que a ratificação da Convenção de Singapura possa, em alguma medida, flexibilizar esta análise, a exemplo do que ocorreu no REsp 700.114/MT, em que foi possível o "reconhecimento da executividade de determinados títulos (contratos eletrônicos) quando atendidos especiais requisitos, em face da nova realidade comercial com o intenso intercâmbio de bens e serviços em sede virtual” (BRASIL, 2007). 
As mediações internacionais fazem parte deste contexto de globalização econômica, que na observância de critérios objetivos da Convenção, como a assinatura do mediador ou declaração da instituição em que ocorreu a mediação (art. $4^{\circ}$, item 1, b)), permitiriam agilidade nas execuções dos acordos. Além disso, com a ratificação, o Brasil obriga-se a cumprir o tratado, devendo buscar modos de torná-lo eficaz. 25

Cabe reforçar que, ainda que os tribunais possam pedir a tradução e outros documentos que confirmem os requisitos da Convenção de Singapura, a imposição de mais formalidades para a execução do acordo, que acabariam por atrasar o procedimento, é absolutamente contrária aos propósitos da Convenção (SILVESTRI, 2019, p. 194). Violar os requisitos de unificação e subsequente exequibilidade poderia representar, inclusive, um descumprimento da obrigação internacional assumida pelo Brasil.

Assim, considerando todas estas premissas, entende-se que uma interpretação possível e apropriada dos $\S \S 2^{\circ}$ e $3^{\circ}$ do art. 784, CPC, é que, se as partes formalizarem o acordo tomando por fundamento a Convenção, dever-se-á analisar apenas os requisitos previstos nela para se considerar o acordo um título executivo, assim como se analisariam os requisitos da lei estrangeira do local da assinatura.

Trata-se, porém, de discussão ainda não deflagrada nos tribunais brasileiros, especialmente ante a recentíssima assinatura. É tema que precisará ser enfrentado e, até que uniformizado, poderá representar alguma dificuldade executiva e interpretativa.

Passando-se agora aos aspectos relativos ao direito material, outro desafio será determinar qual será a legislação aplicável quanto à interpretação da Convenção. Isso porque a Convenção não esclarece como expressões como "incapacidade" (art. 5\%, item 1, a) devem ser interpretadas ou quais leis as determinariam. 26

No contexto brasileiro, acredita-se que o mais seguro seria se valer dos critérios estipulados pela Lei de Introdução às Normas de Direito Brasileiro (Decreto-Lei ${ }^{\circ}$ 4.657/42), no que concerne ao conflito de leis, dado que se mostra critério mais objetivo e de mais fácil apreensão pelas partes e pelo julgador. Também retrata uma escolha anterior do legislador acerca do que se interpreta possível de se basear quando se deparar com uma situação de

$25 \mathrm{O}$ item 5 do art. $4^{\circ}$ da Convenção impõe que a autoridade competente aja rapidamente.

26 Alguns estudiosos da Convenção, como Chong e Alexander, sugerem múltiplos critérios possíveis, como o validation principle, prezando pela máxima efetividade possível ao acordo, ou o renvoi (CHONG; ALEXANDER, 2019b, p. 89-90). 
dúvida, tendo em mente os demais pilares do ordenamento e princípios constitucionais. Assim, por exemplo, para a verificação da incapacidade, utilizar-se-ia a regra do local de domicílio da pessoa cuja capacidade é questionada.

Quanto à nulidade ou ineficácia ( $\operatorname{art.} 5^{\circ}$, item 1, b), a Convenção determina que deve, na falta de estipulação entre as partes, ser avaliado conforme "a lei considerada aplicável pela autoridade competente da Parte na Convenção onde ocorreu o requerimento para assistência jurídica". Assim, reforçando a hipótese anterior, a LINDB seria a forma mais apropriada de se verificar a validade e a eficácia do acordo, caso o Brasil seja acionado para prestar assistência jurídica. Afinal, é por esta lei que o país define a lei aplicável.

Contudo, aqui encontramos mais um desafio. Isso porque, o art. $9^{\circ}$ da referida lei estipula que "para qualificar e reger as obrigações, aplicar-se-á a lei do país em que se constituírem". Quando decorre de contrato, "reputa-se constituída no lugar em que residir o proponente".

Nesse ponto, há grande dificuldade na definição do local em que o acordo se constituiu, dado que, como já comentado, a Convenção dispensa que seja indicado lugar de celebração, bem como viabiliza a ocorrência dos procedimentos virtuais, sem local específico. Também é complexo identificar o local de quem propôs o acordo nos moldes que se encontra. Isso decorre tanto do próprio processo de mediação, que em geral pressupõe a cooperação na construção do acordo, quanto do princípio da confidencialidade. Assim, o mais aproximado seria considerar o lugar em que reside aquele que propôs o procedimento de mediação que resultou no acordo ou, subsidiariamente, do local do mediador.

Como se nota, todos esses questionamentos poderão bater às portas dos tribunais, gerando longos debates em diferentes instâncias. Isso deflagra mais uma dificuldade do sistema brasileiro: o acúmulo de processos no Poder Judiciário. O CNJ informou que o tempo médio de uma execução é de 4 anos e 6 meses, superior, inclusive, ao tempo para o processo de conhecimento (CNJ, 2017).

Este aspecto é reconhecido também por autores internacionais. Mason (2020), além de sugerir que tais casos sejam tratados diretamente pelo STJ, à semelhança dos casos relacionados à arbitragem, indica que um grande desafio será enfrentar cortes que já estão abarrotadas de casos e ainda terão que assumir novas incumbências em razão da Convenção. Trata-se, portanto, de mais um obstáculo, agora organizacional, que o Poder Judiciário precisará continuar a enfrentar. 
É certo que, como indica Schnabel (2019b, p. 274), as dificuldades expostas nesse capítulo não são exclusivas do Brasil, mas a realidade de diversas jurisdições, em que a execução do contrato pode ser um processo longo e estressante. Nesse sentido, encontrar dificuldade de executar o acordo gera a permanência do risco nas relações comerciais quanto à efetividade dos acordos, enfraquecendo o próprio mecanismo da mediação (VANISOVÁ, 2019, p. 7).

Por outro lado, a maioria dos acordos fruto de mediação que foram desafiados no judiciário, foram validados (VANISOVÁ, 2019, p. 8). Isso demonstra que a mediação não deve ser negligenciada. Conforme discutido nos próprios painéis do evento de assinatura da Convenção, os mecanismos de mediação, arbitragem e processos judiciais devem ser vistos como complementares entre si (CHEW; VIALARD; TAYLOR, 2019, s.p.), cabendo à jurisdição brasileira fazer valer o princípio constitucional de acesso à justiça e dar efetiva liberdade às partes de escolher dentre esses vários modos, com segurança e previsibilidade.

Cabe reforçar, porém, que para alguns autores, como Vanisová (2019, p. 6-7), o enforcement dado pela Convenção a partir de uma moldura unificada é apenas um efeito colateral. O principal objetivo da Convenção seria a promoção da mediação como solução de conflitos comerciais internacionais. Sob este viés, ainda que não fosse possível reconhecer como título executivo extrajudicial, o efeito simbólico remanesceria como mais um avanço no ordenamento jurídico brasileiro, que seria aprofundado com uma abordagem eficaz pelos tribunais nacionais. Por isso, no próximo capítulo, passa-se a analisar como os mediandos podem minimizar os riscos aqui mencionados.

\section{O IMPACTO DA CONVENÇÃO DE SINGAPURA PARA OS MEDIANDOS}

Considerando estes vários desafios de aplicação, aqueles que desejarem se valer da Convenção de Singapura podem tomar algumas precauções para minimizar os riscos envolvidos ou, ao menos, contabilizá-los na elaboração do conteúdo do acordo, caso desejem futuramente executá-lo no Brasil.

O primeiro cuidado é observar que a Convenção ainda não possui obrigatoriedade no país, como colocado acima. Isso indica que mesmo que os requisitos ali estipulados sejam rigidamente seguidos, o cumprimento dos acordos poderá ser frustrado, retornando à necessidade de cumprimento dos requisitos das normativas domésticas. Da mesma forma, deve-se considerar que, mesmo que ratificada, a Convenção ainda será tema novo e com 
debates intensos pela doutrina e jurisprudência, como também já suscitado. Este aspecto deve ser levado em conta na escolha do método adequado à resolução do conflito específico.

Ademais, sugere-se que as partes mencionem, sempre que possível, que desejam que o acordo seja submetido às disposições da Convenção de Singapura. Embora este não seja um requisito para a sua efetiva aplicação, pode minimizar discussões acerca do conhecimento pelas partes da regulamentação ali existente, bem como dos demais requisitos impostos.

Ainda, é importante indicar o local de negócios de cada parte que está sendo considerado para o acordo e o local das obrigações ou objeto do acordo. Isso decorre da necessidade de que seja demonstrada a característica de acordo internacional no momento de sua conclusão. Assim, se as partes concordam com o local de negócios considerado, concordam também que se enquadra no escopo da Convenção. Estas três medidas conjuntas podem minimizar as discussões acerca da aplicabilidade da Convenção.

Outra cautela primordial é documentar a integralidade do acordo de alguma forma, para que ele exista "por escrito", conforme art. $2^{\circ}$, item 2 da Convenção. Neste ponto, porém, não é necessário que seja um documento único ou mesmo físico, podendo ser um documento digital. Chong e Alexander (2019b, p. 48-49) indicam, inclusive, que poderiam ser documentos fragmentados, desde que fosse possível auditá-los ou, ao menos, acessar a informação para referência subsequente, além das respectivas assinaturas. 27 Contudo, reunir todas as informações e composições em um único termo de acordo, ainda que eletrônico, pode ser muito importante quando observadas as possibilidades de rejeição. $\mathrm{O}$ artigo $5^{\circ}$, item 1 , c) da Convenção dispõe acerca da necessidade de que as obrigações sejam claras e compreensíveis, o que pode ser comprometido se fragmentado ou desorganizado. Deve-se também ser suficiente para demonstrar que o acordo é vinculante e definitivo (art. $5^{\circ}$, item 1 , b, II).

Também seria recomendável que as partes definissem o direito material aplicável ao acordo, dada a indefinição de algumas expressões da Convenção (incapacidade, nulidade, ineficácia). Nesse ponto, porém, é importante refletir que esta definição por meio da autonomia da vontade não é reconhecida no Brasil (SPERANDIO, 2005).

27 Dispõe o art. 4", item 1, a) da Convenção de Singapura: “A parte que recorrer ao Termo do Acordo, na base no texto da presente convenção, deverá providenciar à autoridade competente desta Convenção no local onde foi solicitada a assistência: a) O Termo do Acordo assinado pelas partes." 
Atualmente, como refletido acima, vige a lei do local da celebração ou do proponente do contrato. A redação atual do art. $9^{\circ}$ da LINDB retirou a expressão "salvo disposição em contrário", apontando pela exclusão desta alternativa para os contratantes. Tal escolha, porém, vai na contramão dos entendimentos mais modernos, que sinalizam para a valorização da autonomia das partes, como estampado na Convenção de Roma de 1980 e na Convenção do México de 1994, esta interamericana, mas sem ratificação pelo Brasil, que apenas a assinou (DOLINGER; TIBURCIO, 2020, p. 361-363).

Nada obstante, considerando que a Lei da Arbitragem (Lei ${ }^{\circ}$ 9.307/1996) permite expressamente que as partes escolham a lei aplicável, limitando apenas a não contrariedade aos bons costumes e à ordem pública, é plenamente possível suscitar, e mesmo ser futuramente acolhido, que as partes assim possam determinar em relação a seus acordos decorrentes de mediação internacional.

Visando efeito similar, ao escolherem pela mediação (seja institucionalizada ou ad hoc), é proveitoso às partes formalizar as regras aplicáveis ao mediador e ao procedimento. Nesse sentido, é possível recorrer a códigos de conduta do mediador e regulamentos de mediação elaborados por entidades governamentais, instituições reconhecidas ou câmaras de mediação, mencionando-os expressamente em cláusulas de mediação, termos de compromisso de mediação e documentos afins. Assim, ao estipularem previamente o que esperam do mediador e do procedimento, os mediandos têm em mãos parâmetros mais seguros, que podem ser futuramente exigidos. 28 Ademais, é importante a escolha de um mediador capacitado e competente, ciente do seu relevante papel na solução do conflito, ainda que nenhuma credencial específica lhe seja exigida. 29

Passando a outro cuidado, considerando que o art. $6^{\circ}$ da Convenção permite aplicações ou reivindicações paralelas, sugere-se que seja estabelecido um critério de determinação de um local prioritário de execução. Tal medida visa evitar um número exagerado de reinvindicações, criando um ônus para a parte que solicitar a execução em local diverso de

28 Cabe relembrar o art. $5^{\circ}$ item 1 , e) e f) da Convenção, que estabelece motivos relacionados ao mediador para recusa do enforcement pela autoridade competente, os quais já foram analisados no capítulo 2.

29 A fim de cumprir o requisito do art. $4^{\circ}$, item 1, b), a forma mais rápida e eficaz de evidenciar que o acordo resultou da mediação é solicitar a assinatura do mediador no próprio termo de acordo. Contudo, independentemente da forma optada, é relevante a manutenção ou mesmo indicação de algumas informações que permitam identificar o mediador, permitindo posterior contato, para que, ao menos, o art. $4^{\circ}$, item 1, b, IV, possa ser utilizado como referência. 
justificar esta escolha. Não se trata de criar um impeditivo, mas parâmetros à aplicação dos princípios da boa-fé e da razoabilidade.

Além disso, a própria Convenção (art. $6^{\circ}$ ) indica que a autoridade competente de onde o pedido foi requerido pode, se considerar pertinente, adiar a decisão ou exigir da outra parte a prestação de garantia. Contudo, trata-se de mera faculdade do julgador. Cabe reforçar que o art. 24 do $\mathrm{CPC}$ explicitou que "ação proposta perante tribunal estrangeiro não induz litispendência e não obsta a que a autoridade judiciária brasileira conheça da mesma causa e das que lhe são conexas". Dessa forma, fica assentada a possibilidade de executar o acordo no Brasil, mesmo que a execução já tenha sido iniciada em outro país, de modo que os critérios de priorização do local de execução também tomam relevância por este aspecto.

Por fim, sugere-se que a mediação seja acompanhada de um advogado. Isso porque, como destaca Adolfo Braga Neto (1999, p. 97), os advogados são indispensáveis, desde a preparação para a mediação até formalização do acordo. Nesse sentido, os departamentos jurídicos das empresas assumem importante figura (REED, 2019, p. 9), ao poderem sugerir a mediação para economia de tempo e recursos, bem como estipular as cláusulas imprescindíveis, inclusive mediante instruções aos advogados externos. ${ }^{30}$ Em conjunto, estes devem fornecer ao cliente as ferramentas jurídicas passíveis de acomodar os interesses conciliados, com a segurança esperada, inclusive, observando as sugestões dadas neste capítulo.

Muito embora as diversas recomendações feitas aqui não sejam exaustivas, apresentam-se como cautelas para a maior perfectibilização do acordo oriundo da mediação internacional. Busca-se que cada vez mais partes verifiquem a adequação da mediação ao seu conflito, tornando-se mediandos. Afinal, por este método os próprios contratantes podem aumentar a torta, gerar ganhos mútuos, manter e aprofundar as relações, com menores danos colaterais, especialmente o gasto de recursos e tempo.

\section{CONSIDERAÇÕES FINAIS}

30 Recorde-se a importância de que a redação do acordo seja clara, transparecendo os reais interesses das partes, e não ofereça - ou, ao menos, minimize - as dificuldades de ser executado na maior parte das jurisdições. Por isso, sugere-se a busca por profissionais que possuam expertise neste método autocompositivo e em direito internacional. 
A Convenção de Singapura descortinou um novo capítulo no desenvolvimento da mediação enquanto método adequado de solução de conflitos. Sua entrada em vigor trouxe grande entusiasmo, mas também evidenciou diversos desafios a serem enfrentados. Ainda restam dúvidas sobre como se dará a aplicação da Convenção, todavia, será apenas com o surgimento de casos concretos que estas respostas poderão ser debatidas de forma construtiva e com um viés prático.

Para que isso ocorra, é necessário o engajamento dos futuros mediandos na utilização da mediação e da Convenção, tendo consciência dos cuidados a serem tomados e dos benefícios a serem auferidos (maior segurança, previsibilidade e economia de recursos, apenas para citar alguns). Também será de grande valia a colaboração dos Estados-membro (espera-se que o Brasil se torne um em breve) na efetiva execução dos acordos apresentados às suas autoridades competentes.

Com a presença deste espírito cooperativo entre os diversos atores, espera-se que haja uma verdadeira disseminação e consolidação da mediação como um método adequado de resolução de conflitos na seara do comércio internacional e no Brasil.

\section{REFERENCIAS}

ALMEIDA, Diogo A. Rezende de; PANTOJA, Fernanda Medina; ANDRADE, Juliana Loss de. Fundamentos. In: HALE, Durval; PINHO, Humberto Dalla Bernardina de; CABRAL, Trícia Navarro Xavier. O marco legal da mediação no Brasil: comentários à Lei ${ }^{\circ}{ }^{\circ} 13.140$, de 26 de junho de 2015. São Paulo: Atlas, 2016. p. 35-90.

BRAGA NETO, Adolfo. Os advogados, os conflitos e a mediação. In: OLIVEIRA, Ângela (Coord.). Mediação, métodos de resolução de controvérsias, $n^{\circ}$ 1. São Paulo: LTr, 1999. p. 93-100.

BRASIL. Constituição da República Federativa do Brasil de 1988. Disponível em: <http://www.planalto.gov.br/ccivil_03/constituicao/constituicao.htm>. Acesso em: 08 jun. 2021.

BRASIL. Decreto $\mathbf{n}^{\mathbf{0}}$ 4.311, de 23 de julho de 2002. Promulga a Convenção sobre o Reconhecimento e a Execução de Sentenças Arbitrais Estrangeiras. Disponível em: <http://www.planalto.gov.br/ccivil_03/decreto/2002/d4311.htm>. Acesso em: 09 jun. 2021.

BRASIL. Decreto-Lei $\mathbf{n}^{\mathbf{0}}$ 4.657, de 4 de setembro de 1942. Lei de Introdução às normas do Direito Brasileiro. Disponível em: <http://www.planalto.gov.br/ccivil_03/decretolei/del4657compilado.htm>. Acesso em: 09 jun. 2021. 
BRASIL. Lei $\mathbf{n}^{\mathbf{0}}$ 13.105, 16 de março de 2015. Código de Processo Civil. Disponível em: <http://www.planalto.gov.br/ccivil_03/_ato2015-2018/2015/lei/113105.htm>. Acesso em: 09 jun. 2021.

BRASIL. Lei $\mathbf{n}^{\mathbf{0}} \mathbf{1 3 . 1 4 0}$, de 26 de junho de 2015. Dispõe sobre a mediação entre particulares como meio de solução de controvérsias e sobre a autocomposição de conflitos no âmbito da administração pública; altera a Lei $n^{\circ} 9.469$, de 10 de julho de 1997 , e o Decreto $\mathrm{n}^{\circ} 70.235$, de 6 de março de 1972; e revoga o $\S 2^{\circ}$ do art. $6^{\circ}$ da Lei $n^{\circ} 9.469$, de 10 de julho de 1997. Disponível em: <http://www.planalto.gov.br/ccivil_03/_ato2015-2018/2015/lei/113140.htm>. Acesso em: 09 jun. 2021.

BRASIL. Lei $\mathbf{n}^{\mathbf{0}}$ 14.112, de 24 de dezembro de 2020. Altera as Leis $n^{\circ} 11.101$, de 9 de fevereiro de 2005, 10.522, de 19 de julho de 2002, e 8.929, de 22 de agosto de 1994, para atualizar a legislação referente à recuperação judicial, à recuperação extrajudicial e à falência do empresário e da sociedade empresária. Disponível em: <http://www.planalto.gov.br/ccivil_03/_ato2019-2022/2020/lei/L14112.htm>. Acesso em: 09 jun. 2021.

BRASIL. Lei $\mathbf{n}^{\mathbf{0}} \mathbf{1 4 . 1 3 3}$, de $1^{\circ}$ de abril 2021. Lei de Licitações e Contratos Administrativos. Disponível em: <http://www.planalto.gov.br/ccivil_03/_ato2019-2022/2021/lei/L14133.htm>. Acesso em: 09 jun. 2021.

BRASIL. Lei n⿳ 9.307, de 23 de setembro de 1996. Dispõe sobre a arbitragem. Disponível em: 〈http://www.planalto.gov.br/ccivil_03/leis/19307.htm>. Acesso em: 17 jun. 2021.

BRASIL. Ministério da Economia. Brasil assina a Convenção de Singapura sobre mediação internacional. 08 de junho de 2021. Disponível em: $<$ https://www.gov.br/economia/pt-br/assuntos/noticias/2021/junho/brasil-assina-a-convencaode-singapura-sobre-mediacao-internacional>. Acesso: em 19 jun. 2021.

BRASIL. Superior Tribunal de Justiça. REs 700.114/MT 2004/0148477-8. Relator: Min. Luiz Fux. Julgamento: 27/03/2007. Órgão Julgador: T1 - Primeira Turma. Publicação: DJ 14/05/2007. p. 251.

CHEW, Daryl; VIALARD, Chloé; TAYLOR, Ed. Multilateralism, International Collaboration and Rule of Law in an Evolving World. In: Singapore Convention on Mediation Panel Session Report. Island Ballroom, Shangri-La Hotel, Singapore, 7 August 2019. Disponível em: <https://www.singaporeconvention.org/pdf/1-Report-Panel-1.pdf>. Acesso em: 17 jun. 2021.

CHONG, Shouyu; ALEXANDER, Nadja. Singapore convention series: Why is there no 'seat' of mediation? Kluwer Mediation Blog, 1. ${ }^{\circ}$ fev. 2019a. Disponível em: $<$ http://mediationblog.kluwerarbitration.com/2019/02/01/singapore-convention-series-why-isthere-no-seat-of-mediation/>. Acesso em: 08 jun. 2021.

CHONG, Shouyu; ALEXANDER, Nadja. The Singapore Convention on Mediation: A Commentary. In: Global Trends in Dispute Resolution. Netherlands: Kluwer Law International, 2019b. v. 8. 
CONSELHO NACIONAL DE JUSTIÇA. Cadastro Nacional de Mediadores Judiciais e Conciliadores (CCMJ). Disponível em: <https://www.cnj.jus.br/programas-eacoes/conciliacao-e-mediacao/perguntas-frequentes-7/cadastro-nacional-de-mediadoresjudiciais-e-conciliadores-ccmj/>. Acesso em: 28 jun. 2021.

CONSELHO NACIONAL DE JUSTIÇA. Execução judicial demora três vezes mais do que o julgamento. Notícias CNJ, 1. ${ }^{\circ}$ set. 2017. Disponível em: <https://www.cnj.jus.br/a-demorapara-executar-decisao-e-maior-do-que-o-de-julgamento-na-justica/>. Acesso em: 22 jun. 2021.

CONSELHO NACIONAL DE JUSTIÇA. Resolução $\mathbf{n}^{\mathbf{0}} \mathbf{1 2 5}$, de 29 de novembro de 2010. Dispõe sobre a Política Judiciária Nacional de tratamento adequado dos conflitos de interesses no âmbito do Poder Judiciário e dá outras providências. Disponível em: <https://atos.cnj.jus.br/atos/detalhar/156>. Acesso em: 09 jun. 2021.

DOLINGER, Jacob; TIBURCIO, Carmem. Direito internacional privado. 15 . $^{\text {e }}$ ed. Rio de Janeiro: Forense, 2020.

INTERNATIONAL MEDIATION INSTITUTE. Code of Professional Conduct. Disponível em: <https://imimediation.org/practitioners/code-professional-conduct/>. Acesso em: 21 jun. 2021.

KATSH, Ethan; RULE, Colin. What We Know and Need to Know About Online Dispute Resolution. South Carolina Law Review, v. 67, p. 329-344, 2016.

MARINONI, Luiz Guilherme; ARENHART, Sérgio Cruz; MITIDIERO, Daniel. Código de processo civil comentado [livro eletrônico]. $7^{\mathrm{a}}$. ed. São Paulo: Thomson Reuters Brasil, 2021. 6 Mb; Epub.

MASON, Paul. The Singapore Convention and Its Benefits for Brazil. International Mediation Institute (IMI), 27 fev. 2020. Disponível em: $<$ https://imimediation.org/2020/02/27/the-singapore-convention-and-its-benefits-for-brazil/> . Acesso em: 08 jun. 2021.

MAZZUOLI, Valerio de Oliveira. Curso de direito internacional privado. 5. ${ }^{a}$ ed. Rio de Janeiro: Forense, 2021.

PAUMGARTTEN, Michele. Disposições finais. In: HALE, Durval; PINHO, Humberto Dalla Bernardina de; CABRAL, Trícia Navarro Xavier. O marco legal da mediação no Brasil: comentários à Lei no 13.140, de 26 de junho de 2015. São Paulo: Atlas, 2016. p. 229-234.

REED, Lucy. Ultima Thule: Prospects for International Commercial Mediation. NUS Centre for International Law Working Paper 19/03, jan. 2019. p. 1-24. Disponível em: $<$ https://ssrn.com/abstract=3339788>. Acesso em: 17 jun. 2021.

REZEK, Francisco. Direito internacional público: curso elementar. 17. a ed. São Paulo: Saraiva, 2018. 
SCHNABEL, Thimoty. The Singapore Convention on Mediation: A Framework for the Cross-Border Recognition and Enforcement of Mediated Settlements. Pepperdine Dispute Resolution Law Journal, v. 19, n. 1, p. 1-60, 2019a. Disponível em: <https://papers.ssrn.com/sol3/papers.cfm?abstract_id=3239527>. Acesso em: 08 jun. 2021.

SCHNABEL, Timothy. Implementation of the Singapore Convention: federalism, selfexecution and private law treaties. The American Review of International Arbitration, v. 30, p. 265-289, 2019b. Disponível em: <https://ssrn.com/abstract=3320823>. Acesso em: 17 jun. 2021.

SILVESTRI, Elisabetta. The Singapore Convention on Mediated Settlement Agreements: A New String to the Bow of International Mediation? Revista Eletrônica de Processo, v. 13, n. 20, n. 2, p. 189-200, maio/ago. 2019. Disponível em: <https://www.epublicacoes.uerj.br/index.php/redp/article/view/44558/30277>. Acesso em: 17 jun. 2021.

SKILLEN, Laura May. Singapore Convention text in Portuguese. Tradução de: Carla Araújo Demchuk, Paul Eric Mason e Nazareth Serpa. International Mediation Institute (IMI), 29 nov. 2019. Disponível em: <https://imimediation.org/2019/11/29/singapore-convention-textin-portuguese/>. $\quad$ Acesso $\quad$ em: 18 jun. 2021 .

SOARES, Patricia Lamego Teixeira. A internalização dos Tratados Internacionais no Brasil. Cooperação em Pauta, Brasília, n. 51. p. 1-3, maio 2019. Disponível em: $<$ https://www.justica.gov.br/sua-protecao/lavagem-de-dinheiro/institucional-

2/publicacoes/cooperacao-em-pauta/copy3_of_CooperaoemPautaMaio2019.pdf >. Acesso em: 08 jun. 2021.

SPERANDIO, Helena Arriola. O princípio da autonomia da vontade nos contratos internacionais - LICC X Convenção do México de 1994 (CIDIP V). Revista Brasileira de Direito Internacional, Curitiba, v. 2, n. 2, p. 309-320, jul./dez. 2005.

TARTUCE, Fernanda. Mediação nos conflitos civis. 4. ${ }^{\text {a }}$ ed. Rio de Janeiro: Forense; São Paulo: Método, 2018.

TILKIAN, Rubens D. Comentários à Lei de Mediação. São Paulo: Migalhas, 2016.

UNCITRAL. Status: United Nations Convention on International Settlement Agreements Resulting from Mediation. Disponível em: $<$ https://uncitral.un.org/en/texts/mediation/conventions/international_settlement_agreements/s tatus $>$. Acesso em: 17 jun. 2021.

UNCITRAL. UNCITRAL Model Law on International Commercial Mediation and International Settlement Agreements Resulting from Mediation, 2018 (amending the UNCITRAL Model Law on International Commercial Conciliation, 2002). Disponível em: <https://uncitral.un.org/sites/uncitral.un.org/files/media-documents/uncitral/en/annex_ii.pdf>. Acesso em: 17 jun. 2021. 
UNITED NATIONS. United Nations Convention on International Settlement

Agreements Resulting from Mediation. Disponível em:

$<$ https://uncitral.un.org/sites/uncitral.un.org/files/singapore_convention_eng.pdf >. Acesso em: 17 jun. 2021.

VANISOVÁ, Veronika. Current Issues In International Commercial Mediation: Short Note On The Nature Of Agreement Resulting From Mediation In The Light Of The Singapore Convention. Prague Law Working Papers Series, Charles University: Praga, 2019. p. 1-12. Disponível em: <https://papers.ssrn.com/sol3/papers.cfm?abstract_id=3413560>. Acesso em: 17 jun. 2021.

Data da submissão: $31 / 08 / 2021$

Data da primeira avaliação: 20/09/2021

Data da segunda avaliação:13/10/2021

Data da aprovação: 13/10/2021 